\title{
Corrosion Characteristics of 20G in the Environment of Heating Surface in Biomass Boilers
}

\author{
Chen Zong, Qimin Wang and Xinzhang Huang \\ Shenyang Institute of Engineering, Shenyang, China \\ * Corresponding author: nxzongchen@163.com
}

\begin{abstract}
A corrosion experiment with $20 G$ has been carried out by simulating the environment of heating surface in biomass boilers. Corrosion dynamic curves were obtained by mass gain method. Analysis of the corrosion characteristics were combined with the surface morphology. And the surface morphology and chemical composition of the specimen after experiment were analyzed by using the energy dispersive spectrometer (EDS) and scanning electron microscopy (SEM). The result of experiment show that there is certain corrosion resistance in $20 \mathrm{G}$ at a temperature of $500^{\circ} \mathrm{C}$, the corrosion strength of chlorine is greater than sulfur during corrosion process, and the deposition corrosion is dominant.
\end{abstract}

Keywords: biomass boiler, heating surface, chlorine corrosion, deposition corrosion

\section{Introduction}

In order to solve the fossil energy shortage and serious environmental pollution problems, the biomass direct combustion power generation technology was developed in our country in recent years. There are more and more corrosion problems in the process of direct combustion heat utilization with the production of related equipment and research in depth [1-3]. In order to improve the energy utilization efficiency of biomass boiler, the corrosion characteristics research of boiler steel is important to study and prevent the corrosion on the heating surface of biomass boilers.

Most of studies on corrosion characteristics are separate study of gas condition or deposition corrosion, the study of this experiment is include the relationship of flue gas corrosion and deposition corrosion [4]. The research object is No. 20 steel (hereinafter to be referred as 20G), it is high quality low carbon steel, its intensity is low, but the toughness, ductility and weld ability are good. Based on the combustion characteristics of biomass, the corrosion can be divided into flue gas corrosion and deposition corrosion [5]. The simulation experiment system was designed by simulating the simplified environment of flue gas and deposition.

\section{Corrosion Simulation Experiment}

\subsection{Experiment System}

Figure 1 is the experiment system; the quartz crucible is placed in the constant temperature area of the center of pipe heater. The gas environment can be divided into two kinds: the first kind is the gas which for research of effect of chloride on the corrosion properties: $12 \% \mathrm{CO} 2,6 \% \mathrm{O} 2,267 \mathrm{ppm} \mathrm{Cl} 2$, the remainder is $\mathrm{N} 2$; the second kind is he gas which for research of effect of sulfur on the corrosion properties: $12 \% \mathrm{CO} 2,6 \% \mathrm{O} 2$, 90ppm SO2 [6-8], the remainder is $\mathrm{N} 2$. The total gas flow rate is $100 \mathrm{ml} / \mathrm{min}$; the remaining gas is absorbed by $\mathrm{NaOH}$ solution. The environment of surface sediments are four alkali metal salts [1], its quality ratio is $\mathrm{KCl}: \mathrm{NaCl}$ : K2SO4:Na2SO4=63:13:5:1. 
Mixed these four alkali metal salts and produce the solution, and smeared the solution on the specimen to simulate the deposition environment.

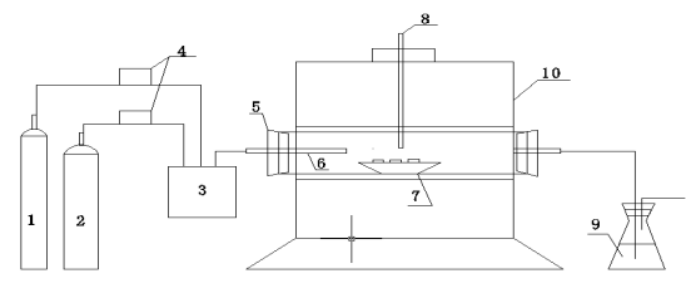

1. $\mathrm{Cl} 2$ or $\mathrm{SO} 2$ 2. O2, CO2, N2 3. Gas Mixing Device 4. Flow Meter 5. Rubber Stopper (High Temperature Resistant) 6. Quartz Tube 7. Quartz Crucible 8. Thermocouple 9. Naoh Solution 10. Electric Heater

\section{Figure 1. Experiment System}

\subsection{Preparation of Specimens}

The $20 \mathrm{G}$ that be made specimen came from boiler pipes of electric power plant, the specimen is $5 \mathrm{~cm}$ per side. It was polished with fine sandpaper, cleaned with the alcohol solution and blot with filter paper. Placing the specimen in the drying cabinet to dry $2 \mathrm{~h}$ at $110^{\circ} \mathrm{C}$. According to the standard $\mathrm{JB} / \mathrm{T}$ 6057-92, the chemical composition (mass fraction, \%) of $20 \mathrm{G}$ is shown in Table 1.

Table 1. The Chemical Composition of 20G

\begin{tabular}{cccccccc}
\hline $\mathrm{C}$ & $\mathrm{Si}$ & $\mathrm{Mn}$ & $\mathrm{P}$ & $\mathrm{S}$ & $\mathrm{Ni}$ & $\mathrm{Cr}$ & $\mathrm{Cu}$ \\
$0.17 \sim 0$. & $0.17 \sim 0$. & $0.35 \sim 0$. & $\leq 0.035$ & $\leq 0.035$ & $\leq 0.30$ & $\leq 0.25$ & $\leq 0.25$ \\
23 & 37 & 65 & & & & & \\
\hline
\end{tabular}

The water content in biomass is based on the biomass species and dryness when it is burn; its numerical change is great. The steam reacts with $\mathrm{Cl}_{2}$ to form $\mathrm{HCl}$, this experiment focus on $\mathrm{Cl}_{2}$, regardless of adding the steam.

\subsection{Experiment Method}

The treated specimens were placed in electric heater and heated between $500^{\circ} \mathrm{C}$ and $650^{\circ} \mathrm{C}$. According to the static oxidation simple test method (ASTM G54-77), it determines the amount of corrosion by using the mass gain method, the corrosion cycle is $24 \mathrm{~h}$. Taking the specimen out every $2 \mathrm{~h}$, and cleaning the specimen surface with distilled water, and placing in the drying cabinet to dry $30 \mathrm{~min}$ at $110^{\circ} \mathrm{C}$. Taking photo of the surface pattern and weighting to obtain the amount of mass gain.

\section{Experiment Results and Analysis}

\subsection{Comparison of Effect on Corrosion Performance at Different Temperature}

3.1.1. Corrosion Dynamic Curves: Figure 2 is the corrosion dynamic curves of $20 \mathrm{G}$ at different temperature in the conditions: gas condition is $12 \% \mathrm{CO} 2,6 \% \mathrm{O} 2,82 \% \mathrm{~N}_{2}$, surface condition is smeared the solution of $\mathrm{KCl}$ : $\mathrm{NaCl}$ : K2SO4: $\mathrm{Na}_{2} \mathrm{SO}_{4}=63: 13: 5: 1$. 


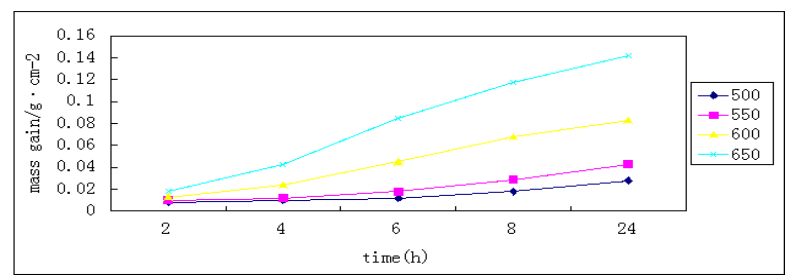

\section{Figure 2. The Corrosion Dynamic Curves of $20 \mathrm{~g}$ at Different Temperature}

As shown in Figure 2, the corrosion of $20 \mathrm{G}$ at different temperature is all in line with the parabolic law [3]. It shown that, 20G has certain corrosion resistance, the mass gain improved with the temperature rose.

The parabolic law can be shown in following formula [4]:

$$
y^{2}=k \bullet t
$$

In the formula: $k$ is parabolic rate constant, it shows corrosion resistance of specimen.

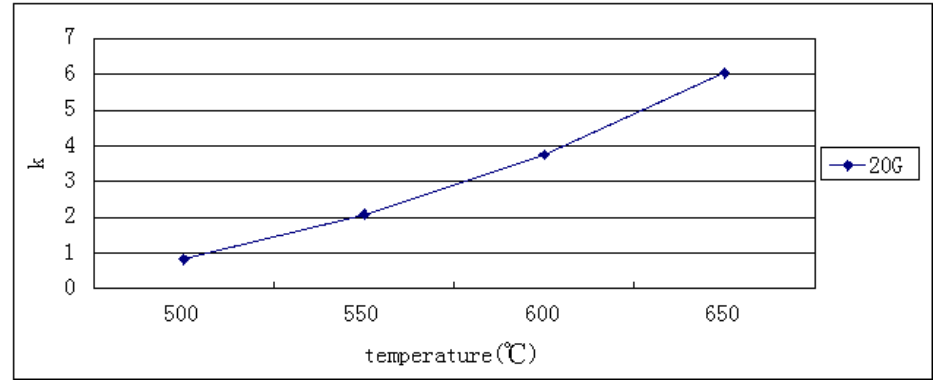

Figure 3. The Relationship of $\mathrm{K}$ and Temperature (20G)

It shown in Figure 3, the corrosion rate is almost a linear relation with the temperature change, the corrosion rate substantial increased with the temperature rose. When the temperature above $550^{\circ} \mathrm{C}$, the corrosion rate increased faster.

3.1.2. Surface Morphology Analysis of Specimens: Figure 4 is macro surface morphology of $20 \mathrm{G}$ at four temperatures after $24 \mathrm{~h}$.

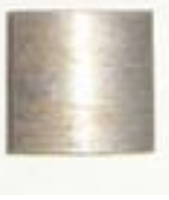

Initial

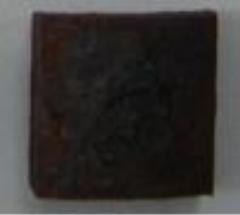

$500^{\circ} \mathrm{C}$

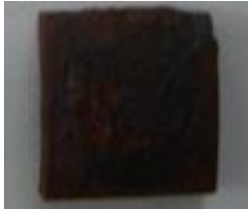

$550^{\circ} \mathrm{C}$

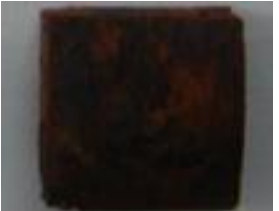

$600^{\circ} \mathrm{C}$

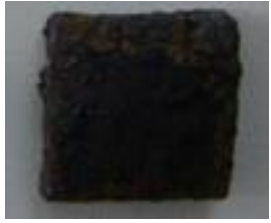

$650^{\circ} \mathrm{C}$

Figure 4. Macro Surface Morphology of $20 \mathrm{~g}$ at Four Temperatures

As shown in Figure 4, the corrosion on the specimen surface is more and more serious, and the corrosion layer is thicker with the temperature rose. At $500^{\circ} \mathrm{C}$ and $550^{\circ} \mathrm{C}$, the corrosion process is slow, the corrosion of specimens increased significantly at $600^{\circ} \mathrm{C}$ and $650^{\circ} \mathrm{C}$. The corrosion is very serious, especially at $650^{\circ} \mathrm{C}$. As shown in the photos, $20 \mathrm{G}$ still has certain corrosion resistant at $500^{\circ} \mathrm{C}$ and $550^{\circ} \mathrm{C}$, its corrosion resistant drops significantly at $600^{\circ} \mathrm{C}$, the specimen almost lost all corrosion resistant at $650^{\circ} \mathrm{C}$.

Figure 5 is surface morphologoes of $20 \mathrm{G}$ at two temperatures after $24 \mathrm{~h}$. As shown in Figure 5 :(1)At $500^{\circ} \mathrm{C}$, there is sheet corrosion layer on the specimen surface, it shows the bulge state. It shows that the corrosion layer layered, loosen and shedding after magnified to 200 times. (2)At $650^{\circ} \mathrm{C}$, there are sheet corrosion products on the specimen surface, the 
amount of holes caused by corrosion increased and deepened, and the corrosion layer of oxide thickened. It shows that the corrosion holes are deep and larger, its lamination is less than $500^{\circ} \mathrm{C}$ as the outer layer has fall off, the rest is inner layer after magnified to 200 times.

Table 2 is the result of element analysis of specimen surface. As shown in Table. 2, the corrosion products are only $\mathrm{Fe}$ and $\mathrm{O}$. The corrosion products at $500^{\circ} \mathrm{C}$ are largely $\mathrm{Fe}_{2} \mathrm{O}_{3}$. According to the law of corrosion reaction, there are also $\mathrm{FeO}$ and $\mathrm{Fe}_{3} \mathrm{O}_{4}$, the layered is clear. At $650^{\circ} \mathrm{C}$, the raise of $\mathrm{Fe}$ content is obvious, $\mathrm{O}$ content reduces. It shows that the shedding of corrosion layer has been serious, the matrix has been exposed.

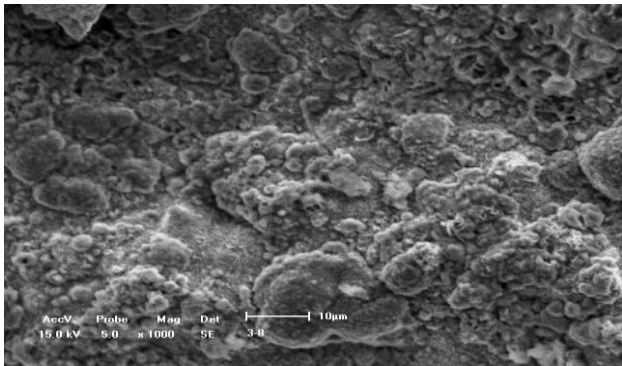

a) $500^{\circ} \mathrm{C}$

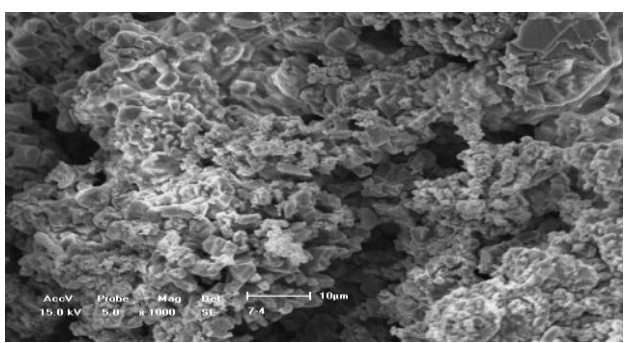

c) $650^{\circ} \mathrm{C}$

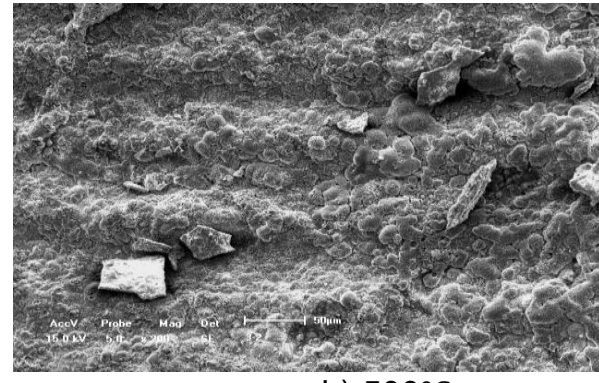

b) $500^{\circ} \mathrm{C}$

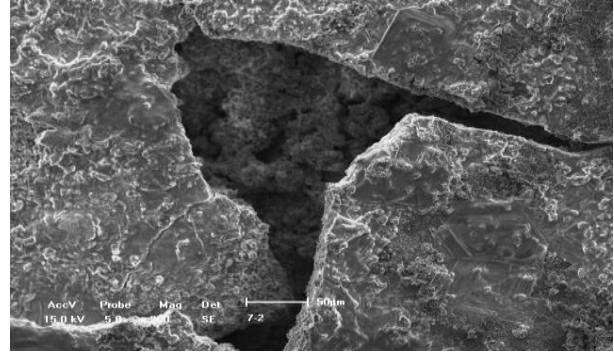

d) $650^{\circ} \mathrm{C}$

Figure 5. Surface Morphologies of $20 \mathrm{~g}$ at Different Temperature after Corrosion for $24 \mathrm{H}$

Table 2. Element Analysis of $\mathbf{2 0 g}$ after Corrosion for $\mathbf{2 4 H}$

\begin{tabular}{ccccccc}
\hline \multirow{2}{*}{$\begin{array}{c}\text { Experimen } \\
\mathrm{t} \text { temperature }\end{array}$} & \multicolumn{7}{c}{ Element atomic percentage } \\
\cline { 2 - 7 } & $\mathrm{O}$ & $\mathrm{Fe}$ & $\mathrm{Cl}$ & $\mathrm{S}$ & $\mathrm{K}$ & $\mathrm{Na}$ \\
\hline \multirow{2}{*}{$500^{\circ} \mathrm{C}$} & 63. & 30. & $/$ & $/$ & 0. & 6.205 \\
& 334 & 133 & & & 328 & \\
$650^{\circ} \mathrm{C}$ & 45. & 43. & 2.753 & $/$ & $/$ & 7.857 \\
\hline
\end{tabular}

\subsection{Comparison of Effect on Corrosion Performance of $\mathrm{O2}$}

3.2.1. Corrosion Dynamic Curves: Figure 2 is the corrosion dynamic curves of $20 \mathrm{G}$ at $600^{\circ} \mathrm{C}$ in the conditions: gas condition is $12 \% \mathrm{CO}_{2}, 6 \% \mathrm{O}_{2}, 82 \% \mathrm{~N}_{2}$ (hereinafter to be referred as flue gas), surface condition is smeared the solution of $\mathrm{KCl}: \mathrm{NaCl}=5: 1$. 


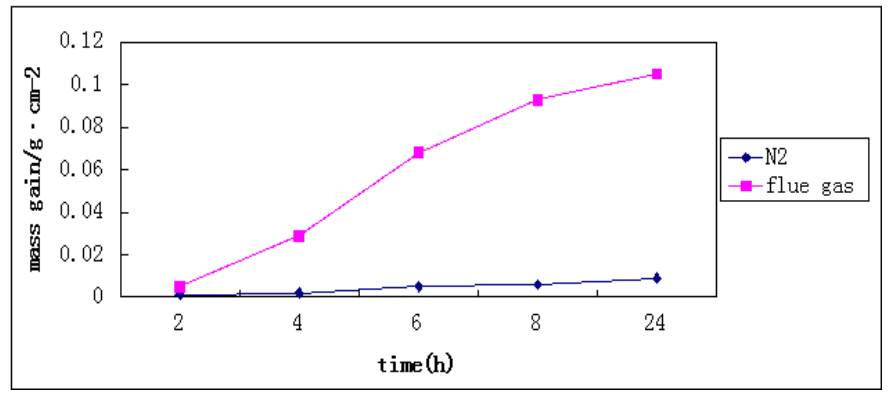

Figure 6. The Corrosion Dynamic Curves of $20 \mathrm{~g}$ in the Condition of Flue Gas and N2

As shown in Figure 6. The corrosion of $20 \mathrm{G}$ in the condition of flue gas is all in line with the parabolic law. There is almost no mass gain in the condition of $\mathrm{N}_{2}$. It shows that $\mathrm{O}_{2}$ plays an important role in corrosion reaction.

3.2.2. Surface Morphology Analysis of Specimens: Figure 7 is surface morphologies of $20 \mathrm{G}$ in the condition of flue gas and $\mathrm{N}_{2}$ after $24 \mathrm{~h}$

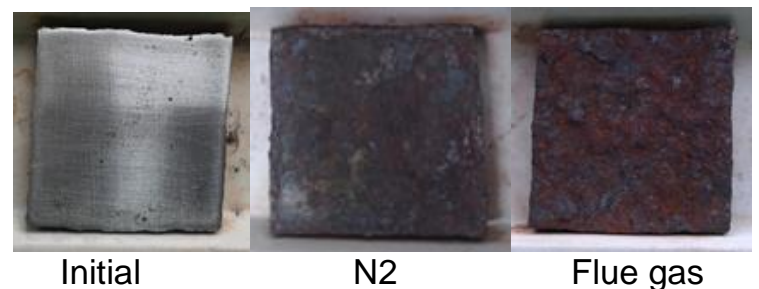

\section{Figure 7. Macro Surface Morphologies of $20 \mathrm{~g}$ in the Condition of Flue Gas and N2}

As shown in Figure 7, an oxide film forms on the specimen surface in the condition of $\mathrm{N}_{2}$ after heating $24 \mathrm{~h}$. The little corrosion of surface can be suspect that the specimen cannot still keep in the condition without $\mathrm{O}_{2}$, the specimens touch the $\mathrm{O}_{2}$ and it produces little corrosion and mass gain.

In the condition of flue gas, for example, the metal chloride on the specimen surface will transform the gas metal chloride at high temperature, and invades the peeling layer surface by loose corrosion surface. The reaction of the metal chloride and the $\mathrm{O}_{2}$ of flue gas on the peeling layer surface can be shown as following formulas [5]:

$$
\begin{array}{r}
3 \mathrm{MCl}_{2}(\mathrm{~g})+2 \mathrm{O}_{2}(\mathrm{~g}) \rightarrow \mathrm{M}_{3} \mathrm{O}_{4}(\mathrm{~s})+3 \mathrm{Cl}_{2}(\mathrm{~g}) \\
2 \mathrm{MCl}_{2}(\mathrm{~g})+(3 / 2) \mathrm{O} 2(\mathrm{~g}) \rightarrow \mathrm{M}_{2} \mathrm{O}_{3}+3 \mathrm{Cl}_{2}(\mathrm{~g})
\end{array}
$$

In the formula: $\mathrm{M} \in\{\mathrm{Fe}, \mathrm{Cr}$, and $\mathrm{Ni}\}$

The metal chloride and $\mathrm{O}_{2}$ products the $\mathrm{Cl}_{2}$ in the above reactions, $\mathrm{Cl}_{2}$ invades the peeling layer surface and products the metal chloride with the metal that failed to act, it intensifies the reaction. Thus, $\mathrm{O}_{2}$ plays an important role in corrosion reaction, and the circular reaction is the main cause of the $\mathrm{Cl}_{2}$ being not consumed.

\subsection{Comparison of Effect on Corrosion Performance of $\mathrm{Cl}$ and $\mathrm{S}$}

3.3.1. Corrosion Dynamic Curves: Figure 8 is the corrosion dynamic curves of $20 \mathrm{G}$ at $500^{\circ} \mathrm{C}$ in four conditions.

(1-2)The gas phase condition is flue gas, surface conditions are smeared the solution of $\mathrm{KCl}: \mathrm{NaCl}=5: 1$ (hereinafter to be referred as chloride) and $\mathrm{K}_{2} \mathrm{SO}_{4}: \mathrm{Na}_{2} \mathrm{SO}_{4}=5: 1$ (hereinafter to be referred as sulfate). 
The simple gas phase condition is $12 \% \mathrm{CO}_{2}, 6 \% \mathrm{O}_{2}, 267 \mathrm{ppm} \mathrm{Cl}_{2}$; the remainder is $\mathrm{N}_{2}$ (hereinafter to be referred as $\mathrm{Cl}_{2}$ ).

The simple gas phase condition is $12 \% \mathrm{CO}_{2}, 6 \% \mathrm{O}_{2}, 90 \mathrm{ppm} \mathrm{SO}_{2}$; the remainder is $\mathrm{N}_{2}$ (hereinafter to be referred as $\mathrm{SO}_{2}$ ).

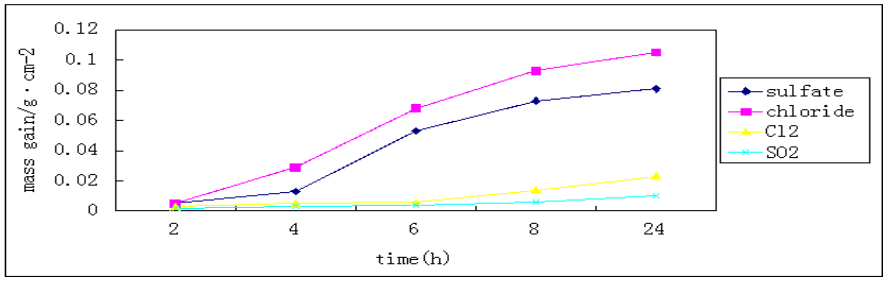

Figure 8. The Corrosion Dynamic Curves of $20 \mathrm{~g}$ in Four Conditions

As shown in Figure 8. The corrosion of $20 \mathrm{G}$ in four conditions is all in line with the parabolic law. After compared the corrosion dynamic curves of sulfate and chloride, it shows that the strength of chlorine corrosion is greater than sulfur corrosion, as the chlorinity is greater than sulfur content in the biomass. But the corrosion ability of chlorine probable is better cannot be ruled out. After compared the corrosion dynamic curves of $\mathrm{Cl}_{2}$ and $\mathrm{SO}_{2}$, it shows the same result.

3.3.2. Surface Morphology Analysis of Specimens: Figure 9 is surface morphologies of $20 \mathrm{G}$ in four conditions after $24 \mathrm{~h}$.

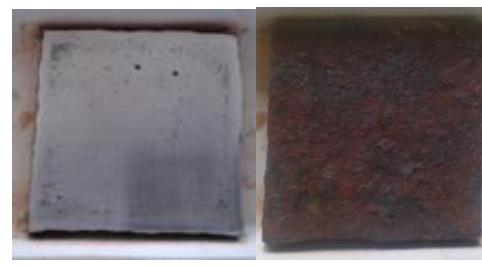

Initial

Chloride

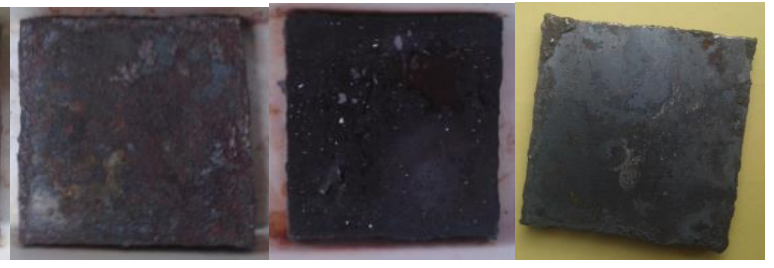

Sulfate

$\mathrm{Cl} 2$

$\mathrm{SO} 2$

Figure 9. Macro Surface Morphologies of $20 \mathrm{~g}$ in Four Conditions

As shown in Figure 9, the corrosion degree of chloride is the highest in four conditions. After compared the principle of sulfur corrosion with formula (2) and (3), the sulfur is consumed continuously in the corrosion reaction, but the chloride maintain certain quantity as the circular reaction. It shows that the corrosion ability of chlorine is stronger than sulfur in the corrosion reaction of heating surface.

\subsection{Comparison of Effect on Corrosion Performance of Flue Gas and Deposition}

3.4.1. Corrosion Dynamic Curves: Figure 10 is the corrosion dynamic curves of $20 \mathrm{G}$ at $500^{\circ} \mathrm{C}$ in three conditions.

(1) The simple gas phase condition is " $\mathrm{SO}_{2}$ ".

(2) The gas phase condition is flue gas, surface condition is smeared the solution of sulfate.

(3) The gas phase condition is " $\mathrm{SO}_{2}$ ", surface condition is smeared the solution of sulfate. 


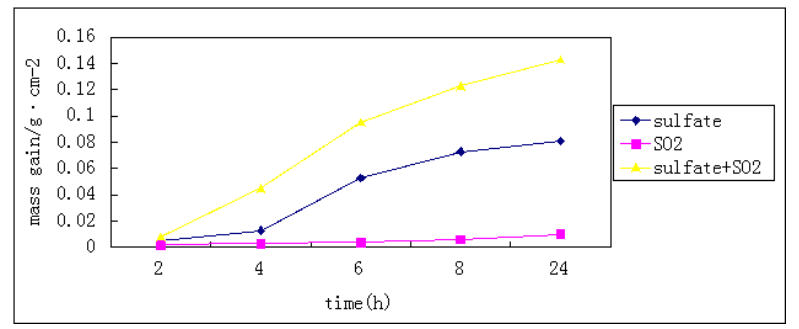

Figure 10. The Corrosion Dynamic Curves of $20 \mathrm{~g}$ in Three Conditions

As shown in Figure 10, the mass gain of deposition corrosion is higher than the simple gas condition of " $\mathrm{SO}_{2}$ ". Here gives a speculation that the ratio of deposition corrosion is more than the flue gas corrosion during the corrosion reaction.

After compared the sulfate $+\mathrm{SO}_{2}$ with above two conditions, it shows that its mass gain is higher than the sum of $\mathrm{SO}_{2}$ and sulfate. According to the experiments before and reference [7], the oxidation film of specimen surface has certain corrosion resistant at the beginning of corrosion reaction. But the oxidation film will be destroyed when the corrosion chemicals in the flue gas reach the surface and accumulate. It probable layered and fell off from the metal surface with the dual role of gas and molten salt eutectic compound. The metal matrix will exposes after the shedding and accelerates the corrosion reaction. As $\mathrm{K}$ is rich in alkali metal salt, the particles of fly ash will be more viscosity and lower melting point, the deposition will be further intensified.

It follows that the flue gas corrosion and deposition corrosion probable promotes each other in the corrosion reaction and intensifies it.

\section{Conclusions}

(1) The corrosion of $20 \mathrm{G}$ in different conditions is all in line with the parabolic law.

(2) $20 \mathrm{G}$ is suitable for using at $500^{\circ} \mathrm{C}$, it almost lost all corrosion resistant above $600^{\circ} \mathrm{C}$.

(3) $\mathrm{O}_{2}$ plays an important role in corrosion reaction; the speculation is the concentration of $\mathrm{O}_{2}$ has certain influence on corrosion rate.

(4) Chlorine corrosion plans major investment in the corrosion reaction, whether gas phase or solid phase.

(5) The ratio of deposition corrosion is more than the flue gas corrosion during the corrosion reaction, these two probable promote each other in the corrosion reaction and intensifies the corrosion reaction.

\section{Reference}

[1] X. H. Zhang, "High Temperature Corrosion Mechanism and Protection on Heating Surface of Straw Fuel Boiler, (PHD thesis)", Shenyang University of Technology, (2012).

[2] J. Luo, S. L. Hou and L. X. Zhao, "Experimental Study on Combustion and Emission Characteristics of Biomass Pellets", Transactions of the CSAE, vol. 26, (2010), pp. 220.

[3] C. J. Yu, Z. Y. Luo, and W. N. Zhang, "Inorganic Material Emission during Biomass Pyrolysis", Journal of Fuel Chemistry and Technology, vol. 28, (2000), pp. 420.

[4] Y. Jiamin and W. Zhansong, "Corrosion Characteristic of 12Cr1MoVG Subjected to Atmosphere of Super heaters in Biomass Boilers", Power System Engineering, vol. 24, (2008).

[5] M. Xiaoqian, "High Temperature Corrosion and Countermeasure of S, Cl and Its Chemical Compound on Refuse Incineration Boiler", Power System Engineering, vol. 13, (1997), pp. 38.

[6] H. P. Nielsen, L. L. Baxter and G. Sclippab, "Deposition of Potassium Salts on Heat Transfer Surfaces in Straw-fired Boilers", A Pilot-scale Study, Fuel, vol. 131, (2000), pp. 79.

[7] H. P. Nielsen, "Deposit and High - Temperature Corrosion in Biomass - fired Boilers", Copenhagen, Department of chemical Engineering of Technical University of Denmark, (1998). 
[8] M. H. Li, "High temperature corrosion of metal", Beijing, Metallurgical Industry Press, (2001).

[9] Q. M. Wang, X. H. Zhang and H. R. Yang, "Mechanism of Biomass Ash Fouling and Pit Corrosion in the Low Temperature Surface", Research and Development, vol. 2, no. 1, (2011).

[10] X. Q. Ma, "The New Development on the Study of Problems with Alkali metals During Straw Combustion”, Water Conservancy \& Electric Power Machinery, vol. 28, no. 28, (2006).

\section{Authors}

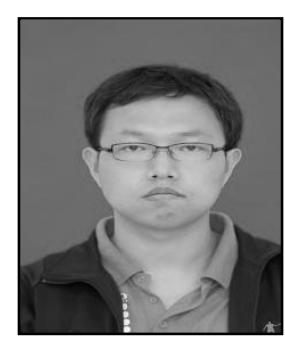

Chen Zong, is studying for a master degree in Power Engineering of Shenyang Institute of Engineering. His research interests include anti-corrosion of boiler.

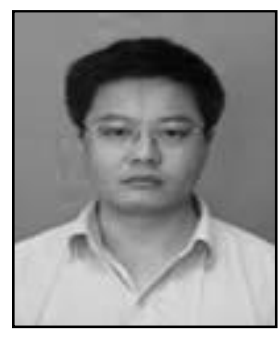

Qimin Wang, Professor of Shenyang Institute of Engineering, graduated from the Department of thermal engineering at Tsinghua University. The studies are focused on the biomass boilers, the industrial boilers and clean coal technologies.

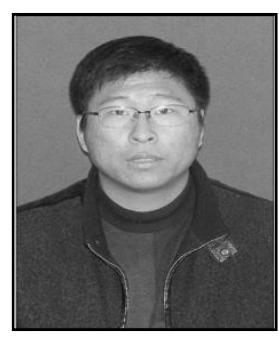

Xinzhang Huang, is studying for a doctor degree in Northeastern University. His research interests include clean combustion technologies. . 